\title{
LÍVIA DE SOUZA TOLENTINO
}

Estudo clínico randomizado e controlado de implantes de diâmetro reduzido confeccionados em titânio puro e uma liga de titânio/zircônio instalados em áreas de molares inferiores: resultados de 1 ano de acompanhamento 


\section{LÍVIA DE SOUZA TOLENTINO}

Estudo clínico randomizado e controlado de implantes de diâmetro reduzido confeccionados em titânio puro e uma liga de titânio/zircônio instalados em áreas de molares inferiores: resultados de 1 ano de acompanhamento

\section{Versão Original}

Tese apresentada à Faculdade de Odontologia da Universidade de São Paulo, para obter o título de Doutor, pelo Programa de Pós-Graduação em Ciências Odontológicas.

Área de concentração: Periodontia

Orientador: Prof. Dr. Luiz Antonio Pugliesi Alves de Lima 
Autorizo a reprodução e divulgação total ou parcial deste trabalho, por qualquer meio convencional ou eletrônico, para fins de estudo e pesquisa, desde que citada a fonte.

Catalogação da Publicação

Serviço de Documentação Odontológica

Faculdade de Odontologia da Universidade de São Paulo

Tolentino, Lívia de Souza.

Estudo clínico randomizado e controlado de implantes de diâmetro reduzido confeccionados em titânio puro e uma liga de titânio/zircônio instalados em área de molares inferiores: resultados de 1 ano de acompanhamento / Lívia de Souza Tolentino; orientador Luiz Antonio Pugliesi Alves de Lima. -- São Paulo, 2014.

42p. : fig., tab. ; $30 \mathrm{~cm}$.

Tese (Doutorado) -- Programa de Pós-Graduação em Ciências Odontológicas Área de concentração - Periodontia. -- Faculdade de Odontologia da Universidade de São Paulo.

Versão original.

1. Implantes dentários. 2. Titânio - Odontologia. 3. Zircônio - Odontologia. 4. Radiografia periapical.

5. Remineralização dentária. I. Lima, Luiz Antonio Pugliesi Alves de II. Título. 
Tolentino LS. Estudo clínico randomizado e controlado de implantes de diâmetro reduzido confeccionados em titânio puro e uma liga de titânio/zircônio instalados em áreas de molares inferiores: resultados de 1 ano de acompanhamento. Tese apresentada à Faculdade de Odontologia da Universidade de São Paulo para obtenção do título de Doutora em Periodontia.

Aprovado em:

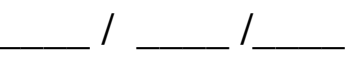

Banca Examinadora

$\operatorname{Prof}(a) \cdot \operatorname{Dr}(a)$.

Instituição: Julgamento:

$\operatorname{Prof}(\mathrm{a}) . \operatorname{Dr}(\mathrm{a})$.

Instituição: Julgamento:

$\operatorname{Prof}(a)$. Dr(a).

Instituição: Julgamento:

Prof(a). Dr(a).

Instituição: Julgamento:

Prof(a). Dr(a).

Instituição: Julgamento: 


\section{AGRADECIMENTOS ESPECIAIS}

Agradeço a Deus por minha vida, pela saúde e determinação a mim dadas, pela Sua proteção e Seu imensurável amor, sem os quais seria impossível superar as dificuldades e alcançar meus objetivos.

Aos meus pais, Adão e Sônia que, com muito esforço e confiança, sempre me acompanham e me incentivam a batalhar pelos meus sonhos, sonhos esses que os tomam como seus. A vocês que tanto amo, todo o meu respeito e gratidão.

Aos meus irmãos Elen e Eduardo, pela paciência, carinho e ajuda durante os momentos mais difíceis. Eu amo vocês.

Ao meu noivo e maior companheiro Guilherme, pelo apoio, amor e incentivo. Amo você. 


\section{AGRADECIMENTOS}

Meu agradecimento ao meu orientador Prof Dr. Luiz Antonio Pugliesi Alves de Lima, pela orientação e incentivo na realização deste trabalho, bem como por ter acreditado e confiado sempre no meu potencial. Muito obrigada.

Ao Prof Dr. Mauricio Guimarães Araújo, meu profundo respeito e admiração ao exemplo de profissional, de caráter e conduta. Foi uma honra poder acompanhá-lo e partilhar de sua sabedoria, que é por mim e por muitos absolutamente reconhecida. Foram 9 anos de uma trajetória de muito incentivo e apoio, sou extremamente agradecida.

Ao Prof Dr. Claudio Mendes Pannuti, sempre atencioso e prestativo. Obrigada por todo apoio, sem sua ajuda tudo seria mais difícil.

Ao Prof Dr. Giuseppe Alexandre Romito, por toda atenção e compreensão nas horas mais difíceis. Além disso, um professor admirável.

Ao prof Dr. João Batista Cesar Neto, pela atenção, conhecimentos compartilhados e amizade, obrigada.

Ao prof Dr. Marcelo Cavalcanti, por todo tempo e conhecimento a mim dado. 
Aos professores Francisco Emílio Pustiglioni, Giorgio de Micheli, Marco Antônio Paupério Georgetti, Marinella Holzhausen, Marina Clemente Conde e Luciana Saraiva de Campos pelos ensinamentos e motivação ao aprendizado.

Aos funcionários do Departamento em especial a Márcia Maria dos Santos, que tanto me socorreu e me ajudou nas horas que mais precisei.

Ao meu amigo Dr. Joao Andrade Garcez Filho, sem o seu suporte nada disso seria possível. Obrigada por acreditar e confiar no meu trabalho.

A minha amiga Flávia Sukekava, que sempre me ajudou, me socorreu e me apoiou de diversas formas. Sou extremamente grata a sua amizade.

A minha grande amiga Adriana Moura Foz, que não mediu esforços para me ajudar, ela tem grande participação no resultado deste trabalho. Muito obrigada.

Ao meu eterno "teacher" Antonio Carlos Correa, um grande incentivador. Obrigada pela contribuição na execução de mais um trabalho.

A Hilana Artese, Adriana Moura Foz, Gislene Sakata, Samuel Ferreira Junior, os amigos os quais convivi estes anos e que hoje considero verdadeiros amigos, os levarei por toda a vida.

Ao meus amigos de doutorado, Mariana Rabelo, Caio Cremonini, Ana Paula “Sassá”, Mariana Rocha, Marcelo Sirolli, Henrique Bueno, Anna Carolina 
Ratto Tempestini Horliana e Leandro Chambrone. Todos os momentos de compreensão e amizade são especiais e muito significativos para minha vida.

A todos os voluntários que participaram desta pesquisa. Muito obrigada pela compreensão e disposição. Sem vocês seria impossível concretizar este trabalho.

E, finalmente, a todos que participaram e colaboraram, direta ou indiretamente, para o desenvolvimento e finalização desta tese. Sozinha não teria êxito nesta caminhada. A todos que tiveram papel importante para a transformação de um desejo em realidade, muito obrigada.

“Aqueles que passam por nós não vão sós, não nos deixam sós. Deixam um pouco de si, levam um pouco de nós." Felipe Cortelline Roque 


\section{RESUMO}

Tolentino LS. Estudo clínico randomizado e controlado de implantes de diâmetro reduzido confeccionados em titânio puro e uma liga de titânio/zircônio instalados em áreas de molares inferiores: resultados de 1 ano de acompanhamento [tese]. São Paulo: Universidade de São Paulo, Faculdade de Odontologia; 2014. Versão Original.

O objetivo do presente estudo clínico randomizado e controlado foi de avaliar e comparar o nível ósseo marginal (NOM) ao redor de implantes de diâmetro reduzido (IDRs - 3,3 mm) confeccionados em uma liga de titânio/zircônio e titânio puro instalados em regiões de molares inferiores após um ano das próteses estarem em função. Dez pacientes participaram do estudo. Em cada paciente um IDR de titânio com adição de zircônio (TiZr; Grupo Teste) e um IDR de titânio puro (Ti; Grupo Controle) foram instalados de forma randomizada em áreas contralaterais de molares inferiores. Após 8 semanas de cicatrização, as próteses metalocerâmicas foram instaladas e os pacientes foram incluídos em um programa de controle de placa bacteriana. Radiografias periapicais foram utilizadas para avaliar o NOM nas faces mesial e distal dos implantes. Essas medidas foram realizadas imediatamente após a instalação das próteses (T1) e um ano após as próteses estarem em função (T2). Além disso, profundidade clínica de sondagem, sangramento à sondagem, supuração, placa bacteriana visível, e mobilidade do implante foram avaliados para a determinação das taxas de sucesso e sobrevivência do implante. Após 1 ano de acompanhamento, a média da mudança do nível ósseo periimplantar marginal nas

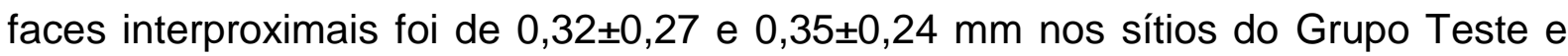
Controle, respectivamente $(p>0,05)$. Não houve diferença estatisticamente significativa entre os grupos. Além disso, não houve falhas nos implantes neste período de acompanhamento e os valores médios das variáveis clínicas estudas também foram similares entre os grupos $(p>0,05)$. Desta forma, este trabalho sugere que IDRs feitos da liga titânio/zircônio ou de titânio puro, podem ser igualmente usados para suportar coroas unitárias em regiões posteriores da mandíbula.

Palavras-chave: Implante de diâmetro reduzido. Nível ósseo marginal. Implantes de titânio. Implantes de zircônio. Radiografia periapical. 


\begin{abstract}
Tolentino LS. One-year follow up of titanium/zirconium alloy $X$ commercially pure titanium narrow-diameter implants placed in the molar region of the mandible: a randomized controlled trial [thesis]. São Paulo: Universidade de São Paulo, Faculdade de Odontologia; 2014. Versão Original.
\end{abstract}

The aim of the present randomized controlled trial study was to analyze marginal bone loss (MBL) and clinical parameters around narrow-diameter implants (NDIs $3.3 \mathrm{~mm}$ ) made of titanium/zirconium alloy (TiZr) in comparison to commercially pure titanium (cpTi) installed in the molar region of the mandible after one year in function. Ten patients participated in the study. A TiZr and a cpTi NDI were randomly installed in contralateral molar sites of the mandible of each patient in a split-mouth design. Eight weeks after healing, all metal-ceramic single crowns were adapted to the implants and patients were enrolled in a plaque control program. MBL at the mesial and distal aspects of the implants were evaluated by comparing periapical radiographs taken immediately after prosthesis installation (T1) and one year after loading (T2). Clinical probing depth, bleeding on probing, suppuration, visible plaque, and implant mobility were evaluated to determine implant success and survival rates. Mean MBL at the interproximal aspects of $\mathrm{TiZr}$ implant sites was $0.32 \pm 0.27 \mathrm{~mm}$, while at cpTi implant sites MBL was $0.35 \pm 0.24 \mathrm{~mm}(p>0.05)$. Both $\mathrm{TiZr}$ and $\mathrm{cpTi}$ NDIs presented $100 \%$ implant survival and success rates, with no significant differences in the clinical parameters studied ( $p>0.05$ ). In conclusion, TiZr and cpTi NDIs presented similar outcomes after one year in function in the molar region of the mandible. The results suggest that $\mathrm{TiZr}$ and $\mathrm{cpTi}$ NDIs may be equally used to support single crowns in the posterior area of the mouth. However, further studies with longer follow-up periods are necessary to confirm these findings.

Keywords: Narrow diameter implant. Marginal bone level. Titanium implants. Zirconium implants. Periapical radiographs. 


\section{LISTA DE FIGURAS}

Figura 4.1 - Imagem radiográfica mostrando um implante TiZr instalado na região de molar inferior (Grupo Teste)

Figura 4.2 - Imagem radiográfica mostrando um implante Ti instalado na região de molar inferior (Grupo Controle).......................................................22

Figura 4.3- Imagem radiográfica mostrando uma coroa metalocerâmica unitária adaptada em um implante de diâmetro reduzido TiZr com um ano de acompanhamento (Grupo Teste)......................................................24

Figura 4.4 - Imagem radiográfica mostrando uma coroa metalocerâmica unitária adaptada em um implante de diâmetro reduzido Ti com um ano de acompanhamento (Grupo Controle).................................................24 


\section{LISTA DE TABELAS}

Tabela 5.1 - Porcentagem (\%) de M, SS, S, PBV, IPB no T1 e T2 .28

Tabela 5.2 - Profundidade clínica de sondagem (PCS) na décima semana de acompanhamento.

Tabela 5.3 - Profundidade clínica de sondagem (PCS) com 1 ano de acompanhamento.

Tabela 5.4 - (a) Resultados do nível ósseo periimplantar marginal observados na radiografia na oitava semana e após 1 ano das próteses em função. (b) Resultados da mudança do nível ósseo periimplantar marginal entre T1 e T2. 


\title{
LISTA DE ABREVIATURAS E SIGLAS
}

\author{
DP Desvio padrão \\ IDR Implante de diâmetro reduzido \\ IPB Índice de placa bacteriana \\ GC Grupo controle \\ GT Grupo teste \\ M Mobilidade \\ NOM Nível ósseo marginal \\ $P \quad$ Valor $p$ \\ PBV Placa bacteriana visível \\ PCS Profundidade clínica de sondagem \\ S Supuração \\ SLA Sandblasted and acid-etched surface (superfície jateada por areia de \\ granulação grossa e condicionada por ácido) \\ SS Sangramento à sondagem \\ $\mathrm{Ti} \quad$ Titânio puro \\ TiZr Titânio/zircônio \\ T1 Imediatamente após a instalação das próteses \\ T2 Um ano após as próteses estarem em função
}




\section{LISTA DE SÍMBOLOS}

$\% \quad$ Porcentagem

$\geq \quad$ Maior ou igual

mg Miligramas

$\mathrm{mm}$ Milímetros 
SUMÁRIO

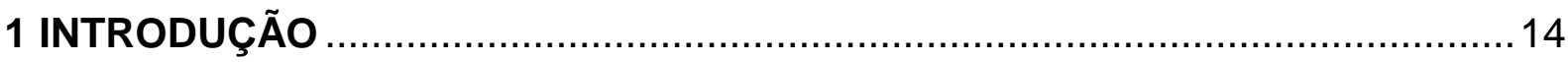

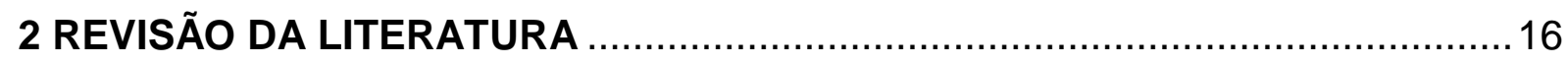

3 PROPOSIÇÃO

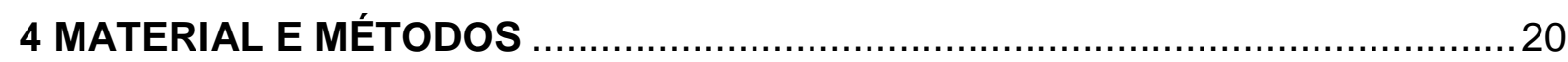

5 RESULTADOS

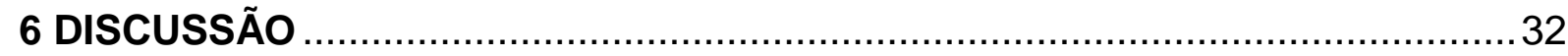

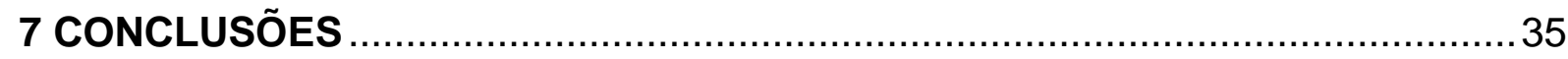

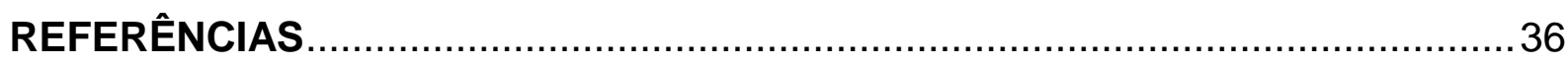

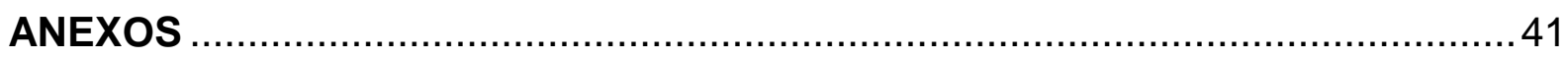




\section{INTRODUÇÃO}

Os implantes dentários têm sido constantemente indicados para suportar diferentes tipos de reconstruções protéticas. No entanto, no início da implantodontia, os implantes eram utilizados apenas para tratar pacientes completamente edêntulos. Depois disso, foram usados para tratar pacientes parcialmente edêntulos com necessidade de repor vários dentes e, por fim, reabilitar pacientes que precisavam de dentes unitários. Em diversos casos, espaços limitados eram observados, decorrentes de situações nas quais, por exemplo, incisivos inferiores e incisivos laterais superiores, necessitavam ser substituídos. Tais situações são particularmente desafiadoras não somente do ponto de vista estético, mas também em relação ao perfil de emergência (Branemark et al., 1985; Albrektsson 1988; Adell et al., 1990; Lekholm et al., 1994).

Pacientes com espaço protético mesio-distal reduzido, agenesia dentária, rebordos diminuídos após extrações, ou com considerável destruição óssea resultante de doença periodontal ou trauma, frequentemente apresentam espessura óssea incompatível com a utilização de implantes de diâmetro regular. Quando a dimensão vestíbulo-lingual é reduzida e a quantidade de osso livre é menor que 4 $\mathrm{mm}$ de espessura, a colocação de um implante de diâmetro regular comumente leva à exposição das roscas do implante. Esta exposição pode não só comprometer a estabilidade do implante, mas também os resultados estéticos da futura restauração (Hammerle et al., 1998; Carlsson et al., 2000; Chiapasco et al., 2001; Nedir et al., 2009). Assim, na tentativa de superar estes desafios, o uso de implantes de diâmetro reduzido (IDRs; $<3,75 \mathrm{~mm}$ ) foi introduzido na prática clínica (Andersen et al., 2001). Além de possibilitar a instalação de um implante em um espaço mesiodistal reduzido, a sua utilização também pode evitar procedimentos cirúrgicos para o aumento do rebordo ósseo, os quais, além de serem mais traumatizantes para o paciente, encarecem e retardam o tratamento.

O titânio puro (Ti) vem sendo amplamente utilizado na confecção de implantes há mais de 40 anos devido às suas propriedades físicas, químicas e biológicas favoráveis (Steinemann 1998; Barter et al., 2012). Contudo, as propriedades mecânicas do $\mathrm{Ti}$ utilizado na fabricação de IDRs parecem ser limitadas. (Davarpanah et al., 2000; Zinsli et al., 2004; Quek et al., 2006; Allum et al., 
2008; Flanagan 2008; Al-Nawas et al., 2012). A principal razão para esta percepção seria o fato de que IDRs possuem uma área de contato osso/implante consideravelmente menor do que implantes com diâmetro regular, comprometendo, assim, a distribuição de forças no tecido ósseo.

Recentemente, foi introduzido no mercado um novo implante de diâmetro reduzido confeccionado em uma liga de titânio/zircônio (TiZr; 83-87\% de Titânio e $13-17 \%$ de Zircônio), o implante Roxolid ${ }^{\circledR}$ (Institut Straumann AG, Basel, Switzerland). Esses implantes, produzidos em diferentes comprimentos (8, 10, 12, e $14 \mathrm{~mm}$ ) e formas (tissue level e bone leve), apresentam um diâmetro de $3,3 \mathrm{~mm}$. Após testes biomecânicos em modelos experimentais, os IDRs de TiZr têm demonstrado atributos mecânicos significantemente superiores aos IDRs de Ti no que diz respeito à resistência à fadiga, osseointegração, dureza, além de uma maior superfície de contato do osso com a superfície do implante (Stone et al., 2009; Sista et al., 2011; Al-Nawas et al., 2012; Gottlow et al., 2012; Saulacic et al., 2012).

Os IDRs são tipicamente indicados para regiões anteriores da cavidade bucal. Entretanto, diversos estudos avaliando o uso de IDRs instalados em regiões posteriores tem sido realizados, tanto da mandíbula quanto da maxila (Garcez et al., 2008; Tolentino et al., 2013; Garcez et al., 2014). Os resultados clínicos dos IDRs foram observados em uma série de casos de 8 e 10 anos de acompanhamento, demonstrando taxas de sucesso de $98 \%$ e $97 \%$, respectivamente. Em um recente estudo clínico controlado e randomizado (Tolentino et al., 2013), o uso de IDRs em regiões posteriores foram avaliados em 42 pacientes que receberam próteses unitárias. Os 21 pacientes que receberam um IDR feito da liga titânio/zircônio e os 21 pacientes que receberam um IDR de titânio puro foram acompanhados por 1 ano após a instalação das próteses. Os resultados deste experimento demonstraram taxas de sucesso e sobrevivência para ambos os grupos de 95\%. Além disso, não houve diferenças significantes entre as variáveis clínicas avaliadas. Entretanto, a despeito dos resultados promissores obtidos até aqui, faltam trabalhos na literatura com um controle metodológico mais rígido (ex. estudo de boca divida), incluindo exames clínicos e radiográficos, que avaliam o uso de IDRs feitos de titânio com adição de zircônio instalados em regiões posteriores da cavidade bucal. 


\section{REVISÃO DE LITERATURA}

Diversos estudos mostraram que a instalação de IDRs é uma alternativa viável na reabilitação das regiões anteriores e posteriores de maxila e mandíbula que apresentam rebordos ósseos com dimensões insuficientes para a colocação de implantes de plataforma regular (Polizzi et al., 1999, Andersen et al., 2001, Vigolo et al., 2004).

De acordo com Polizzi et al. (1999), os IDRs são indicados para regiões onde as forças oclusais e o espaço mesio-distal são pequenos, como é o caso da região de incisivos laterais superiores e incisivos inferiores. No entanto, Comfort et al. (2005) demonstraram em seu estudo que os IDRs também podem ser instalados com sucesso em regiões posteriores. Porém, naquele mesmo estudo, os IDRs instalados foram esplintados com implantes de plataforma regular ou a outros implantes de diâmetro reduzido. Buser e colaboradres em 1990 relataram que a razão para isso parece ter sido originada no conceito de que IDRs não podem neutralizar e distribuir adequadamente as forças geradas pela oclusão na região posterior quando suportam coroas isoladas.

Ao avaliar as falhas nos IDRs relatadas na literatura, estas estavam relacionadas, em sua maioria, com a falta e perda de osseointegração (Andersen et al., 2001), e doenças periimplantares (Romeo et al. 2006). Apenas uma fratura de implante foi relatada (Polizzi et al., 1999), a qual ocorreu após 5 anos de uso da prótese. Alguns problemas ocorreram nas próteses dos IDRs. Contudo, estes não estavam relacionados com o diâmetro do implante instalado, mas sim com os componentes destes implantes (conectores/intermediários). Quando estes problemas aconteceram, os componentes puderam ser facilmente substituídos, sem gerar danos para estabilidade do implante.

Com relação à fadiga de carga dos IDRs, Quek et al. (2006) realizaram um trabalho experimental no qual observaram que quanto menor o diâmetro do implante, maior o potencial de risco à fadiga. A respeito da resistência a fratura, Jorneus (1996) propôs que implantes de diâmetro reduzido possuem resistência a fratura 25\% menor que implantes de plataforma regular, e sugere cautela na instalação de IDRs. Berglundh et al. (2002) revisaram sistematicamente a literatura e constataram que fratura de implante é uma complicação rara $(0,08 \%-0,74 \%)$ no 
suporte de sobredentaduras, próteses fixas parciais ou totais. Já nos implantes que receberam coroas unitárias não houve nenhum relato de fratura de implante.

Em estudos experimentais em ratos, Ivanoff et al. (1997) analisaram os resultados da redução da dimensão e a menor resistência para suportar força de carga de IDRs, não encontrando diferenças significativas na taxa de sobrevivência na comparação com implantes de plataforma regular. Os autores sugerem ainda que IDRs podem obter estabilidade primária mais facilmente do que implantes de plataforma regular, quando instalados em áreas reduzidas de suporte ósseo cortical. Este dado é suportado parcialmente pelos achados de Friberg et al. (2002). Estes autores instalaram implantes com diferentes diâmetros em 92 indivíduos. Após 2 anos de acompanhamento, os resultados indicaram que as complicações de osseointegração estavam relacionadas a qualidade óssea, e não ao diâmetro do implante. Os autores sugeriram que os aspectos biomecânicos da interface osso/implante podem ter um impacto maior na instabilidade dos implantes que o diâmetro em si.

Alguns autores como Esposito et al. (1998a, 1998b) afirmaram que as falhas em implantes estão mais frequentemente relacionadas à problemas biomecânicos e de fabricação do que às doenças periimplantares. Não obstante, no estudo de Romeo et al. (2006), o qual avaliou implantes de diâmetro reduzido (3,3 mm) e implantes de plataforma regular $(4,1 \mathrm{~mm})$, tanto os implantes de plataforma regular quanto os IDRs apresentaram mais complicações biológicas, como periimplantite, do que complicações biomecânicas. Estes autores também confirmaram a confiabilidade do IDRs, os quais apresentaram prognóstico comparável aos implantes de plataforma regular, e relataram que a localização do implante, independente do seu diâmetro, não parece afetar a sua sobrevivência.

$\mathrm{Na}$ tentativa de eliminar as incertezas em relação a previsibilidade dos IDRs quando instalados em áreas posteriores e de garantir uma estabilidade a longo prazo, implantes confeccionados com uma liga de titânio e zircônio foram introduzidos no mercado. Ikarashi et al. (2005), em um trabalho realizado em ratos, avaliaram a resistência a corrosão e as propriedades mecânicas de implantes fabricados com $\mathrm{Ti}$ e TiZr. Os autores analisaram histologicamente a superfície de contato osso/implante, e observaram que existia um menor número de células inflamatórias ao redor dos implantes TiZr quando comparados com implantes Ti. Resultados semelhantes foram encontrados no estudo experimental de Gottlow et al. 
(2012). Os autores avaliaram e compararam a osseointegração, fadiga e estabilidade dos implantes TiZr e Ti em 12 porcos, e concluíram que os implantes $\mathrm{TiZr}$ apresentaram maior estabilidade e, histologicamente, as mesmas propriedades de osteocondutividade que os implantes Ti.

Recentemente, estudos pilotos com implantes TiZr em humanos, começaram a ser realizados com o objetivo de testar sua performance na cavidade bucal quando estes estão em função. Barter et al. em 2011, instalaram 22 implantes TiZr e acompanharam por 2 anos. Depois de análises clínicas e radiográficas, os autores concluíram que os implantes de titânio com adição de zircônio foram considerados seguros e confiáveis. Tolentino et al. (2013), em um estudo prospectivo, avaliaram e compararam clinicamente implantes de titânio/zircônio com implantes de titânio puro instalados em áreas posteriores edêntulas. No exame de acompanhamento de 1 ano, os implantes investigados apresentaram altas taxas de sucesso e sobrevivência. Desta forma os autores concluíram que, em um curto intervalo de tempo, tanto os IDRs confeccionados com a liga de titânio/zircônio quanto os de titânio puro podem ser utilizados para suportar coroas unitárias em regiões posteriores dos maxilares. 


\section{PROPOSIÇÃO}

O objetivo deste estudo clínico randomizado e controlado foi de avaliar a perda óssea marginal ao redor de implantes de diâmetro reduzido confeccionados em uma liga de titânio com adição de zircônio em comparação com titânio puro instalados em regiões de molares na mandíbula com um ano de acompanhamento após as próteses estarem em função. Além disso, as taxas de sucesso e sobrevivência dos diferentes IDRs foram calculados. 


\section{MATERIAL E MÉTODOS}

\section{Seleção dos voluntários:}

O presente estudo clínico, prospectivo, boca dividida, randomizado e controlado foi iniciado após a aprovação pelo Comitê de Ética em Pesquisa em Humanos da Universidade Federal de Sergipe, Brasil e pela Universidade de São Paulo, Brasil (Anexos A e B). Todos os pacientes assinaram um termo de consentimento no início do tratamento, autorizando o uso de qualquer material didático, dados clínicos e radiográficos e fotografias referentes ao tratamento, para uso em pesquisas clínicas. Dez pacientes que necessitavam de reabilitação protética de dentes unitários em regiões de molares inferiores foram incluídos na pesquisa. A amostra foi calculada com ajuda de um programa estatístico (BioEstat 5.0 - Editora do instituto de desenvolvimento sustentável de Mamirauá, Amazonas, Brasil). Para o cálculo amostral foi considerada uma diferença entre os grupos de 0,5 mm no desfecho primário (perda óssea radiográfica após um ano), desvio padrão de 0,5 mm (Al-Nawas et al., 2012), e poder de teste e nível de significância de 0,80 e 0,05 , respectivamente. Para tanto, foi utilizado o Teste t de Student para amostras pareadas bilateral. Os pacientes foram atendidos em uma clínica privada em Aracajú, Brasil, no período de Outubro de 2011 a Outubro de 2012.

Os seguintes critérios de inclusão foram preenchidos por todos os participantes: (i) apresentar 2 áreas de molares inferiores contralaterais edêntulas; (ii) apresentar dente antagonista hígido; (iii) espaços endêntulos entre dentes hígidos; (iv) exibir espessura óssea de no mínimo $5 \mathrm{~mm}$ e altura óssea de no mínimo $8 \mathrm{~mm}$; (v) ter no mínimo 18 anos de idade; e (vi) pacientes com disponibilidade de acompanhamento trimestral durante, no mínimo, 1 ano após as próteses estarem em função.

Os critérios de exclusão foram os seguintes: (i) procedimento de aumento ósseo prévio a instalação do implante; (ii) presença de periodontite não tratada; (iii) alterações em tecido mole e/ou duro; (iv) uso de drogas que pudessem afetar o metabolismo ósseo (ex. biofosfonados); (v) uso abusivo de álcool e tabaco (>10 cigarros/dia); (vi) indivíduos imunocomprometidos (HIV, AIDS, terapia com drogas imunossupressoras); (vii) grávidas; (viii) presença de hábitos parafuncionais; e (ix) histórico de radioterapia de cabeça e pescoço. 


\section{Delineamento experimental:}

Dez pacientes foram selecionados para receber dois implantes na região de molares da mandíbula (4 homens e 6 mulheres, com a média de idade de 43,3 anos). De um lado da mandíbula um implante TiZr (Grupo Teste - GT; Roxolid ${ }^{\circledR}, 3,3$ $\mathrm{mm}$ de diâmetro de corpo e 4,8 mm de diâmetro de plataforma, tissue level, Instituto Straumann AG, Basel, Suécia) foi instalado (Figura 4.1). Enquanto que no lado contralateral, um implante Ti (Grupo Controle - GC; SLActive ${ }^{\circledR}, 3,3$ mm de diâmetro de corpo e 4,8 mm de diâmetro de plataforma, tissue level, Instituto Straumann AG, Basel, Suécia) foi instalado (Figura 4.2). A randomização dos implantes foi realizada por um sorteio no momento da exposição óssea durante a cirurgia. Optou-se por uma randomização simples por ser um estudo de boca dividida e amostra homogênea. A randomização foi realizada por um membro da equipe clínica que não participou diretamente do estudo.

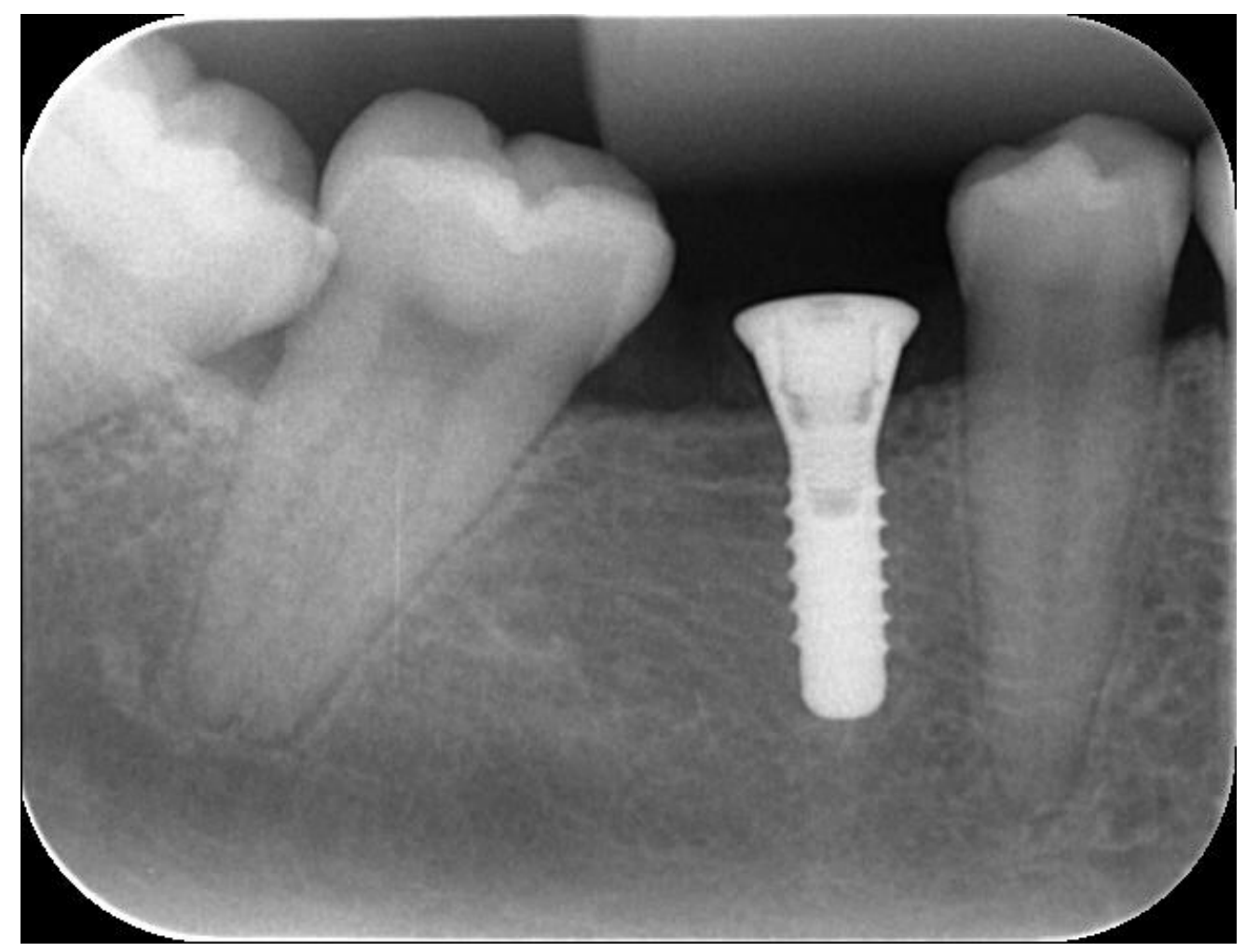

Figura 4.1- Imagem radiográfica mostrando um implante TiZr instalado na região de molar inferior (Grupo Teste) 


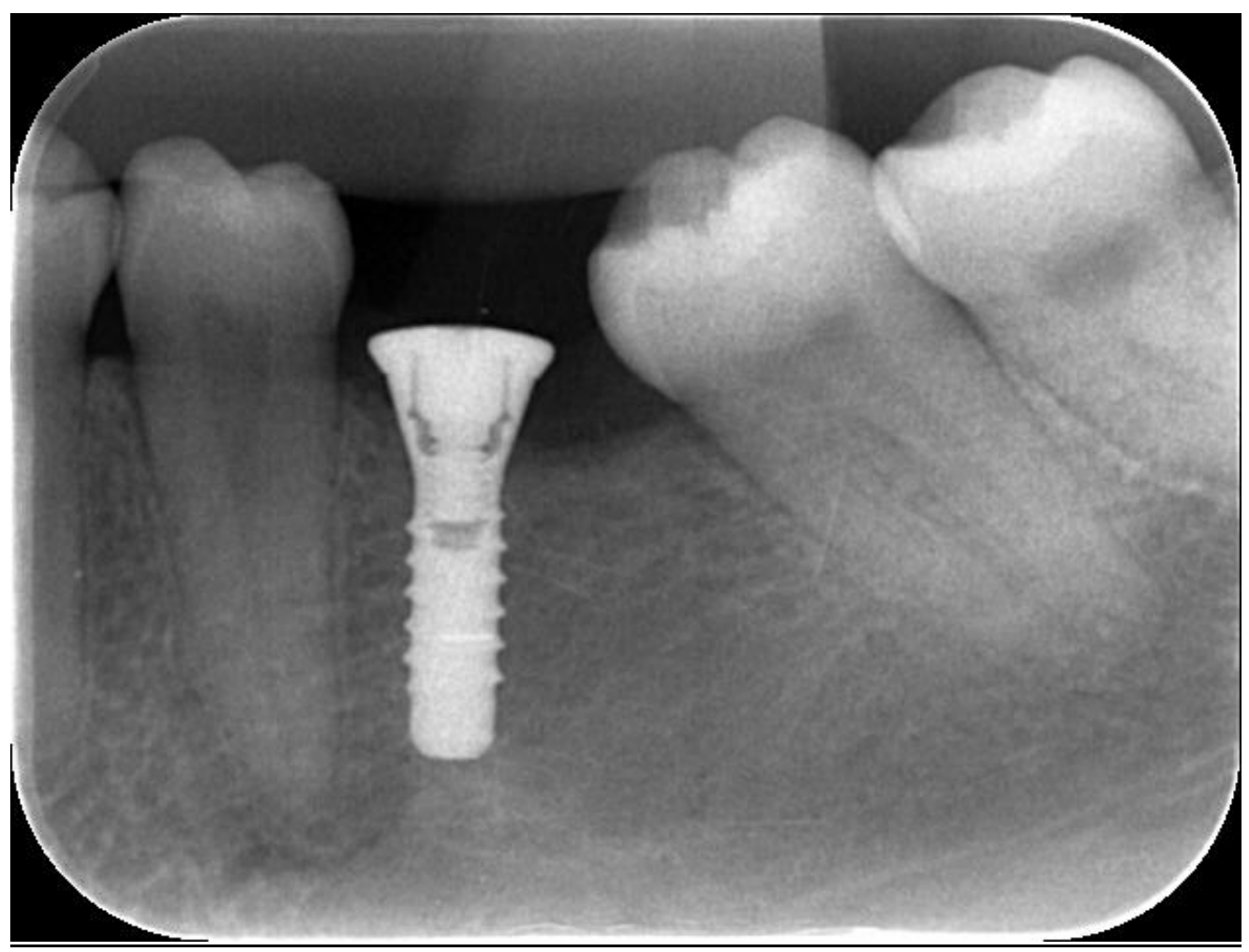

Figura 4.2 - Imagem radiográfica mostrando um implante de diâmetro reduzido Ti instalado na região de molar inferior (Grupo Controle)

\section{Procedimento cirúrgico:}

Os procedimentos cirúrgicos foram realizados sob anestesia com mepivacaína $2 \%$ com vasoconstritor (Noradrenalina 1:100.000). Após a anestesia local, uma incisão na crista foi realizada e um retalho total foi elevado. Subsequentemente, os implantes foram instalados de acordo com as instruções do fabricante e os parafusos de recobrimento foram fixados sobre cada implante. Em seguida, o retalho foi reposicionado e mantido em posição com suturas interrompidas de tal forma que se obteve uma instalação de implante semisubmersa. As suturas foram removidas 10 dias após a instalação do implante. Os pacientes foram medicados por via oral com diclofenaco de potássio (50 mg), 8/8 horas por 3 dias e dipirona sódica (500 mg), 35-40 gotas de 6/6 horas, em caso de dor. Além disso, foi recomendado o uso de digluconato de clorexidina $(0,12 \%), 12 / 12$ horas por 15 dias. Todos os procedimentos cirúrgicos foram realizados pelo mesmo cirurgião.

Depois de um período de 8 semanas de cicatrização, a cabeça dos implantes foi moldada de acordo com as instruções do fabricante e coroas unitárias 
metalocerâmicas parafusadas foram confeccionadas e instaladas. Os pacientes foram incluídos em um programa de controle de placa bacteriana, que envolveu instrução de higiene bucal com escovas interproximais e enxaguatório bucal, e tratamento profilático no consultório nas visitas de 3, 6, 9 e 12 meses após a instalação das próteses. A presença de contato oclusal das coroas metalocerâmicas foi confirmada com o auxílio de tiras de carbono.

\section{Desfecho primário}

As variáveis de desfecho primário usadas neste estudo foram as diferenças do nível ósseo marginal (NOM) ao redor dos implantes e as taxas de sucesso e sobrevivênvia dos IDRs.

Todas as radiografias periapicais foram realizadas com posicionadores radiográficos não-personalizados em uma mesma clínica radiológica, com o mesmo equipamento (Planmeca ProMax ${ }^{\circledR}$, Planmeca, Helsinque, Finlândia), e pelo mesmo operador. O processamento das radiografias foi realizado manualmente e todos os cuidados para uma padronização na revelação foram realizados. As radiografias foram digitalizadas usando um scanner profissional (CanoScan 9950F da Canon Inc, China) que foram armazenadas como arquivos TIFF. Os arquivos foram numerados para cada paciente e nomeados conforme o respectivo lado (ou seja, esquerda ou direita), de acordo com o de tempo de avaliação. Nas faces mesiais e distais de cada implante, a distância entre o ombro do implante e o primeiro contato osso/implante, imediatamente após a instalação das próteses (T1) e um ano após as próteses estarem em função (T2; Figuras 4.3 e 4.4) foi mensurada com o auxílio de um programa de computador (Image $J^{\circledR}$, National Institutes of Health, 1997), e a média foi obtida para cada implante. 


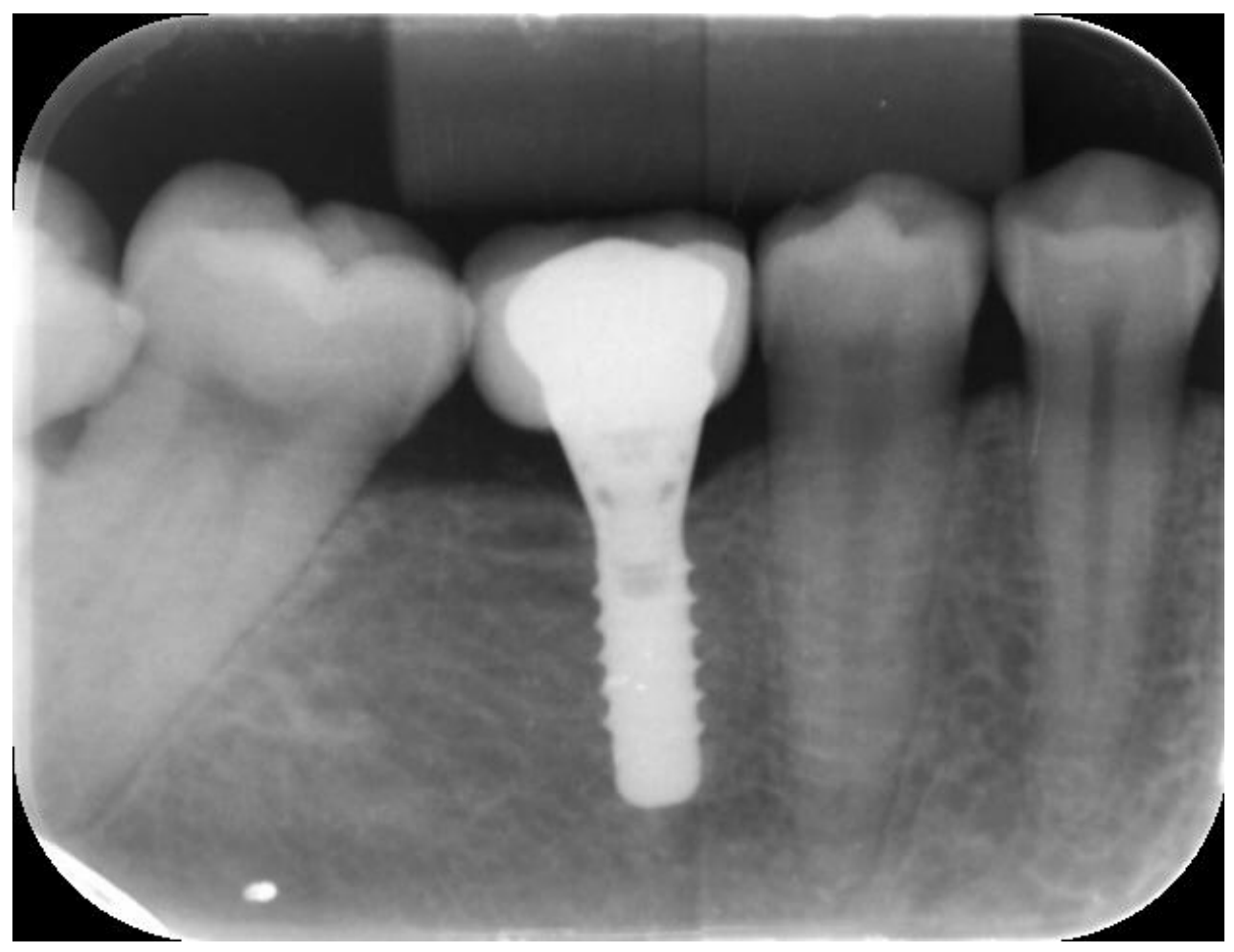

Figura 4.3- Imagem radiográfica mostrando uma coroa metalocerâmica unitária adaptada em um implante de diâmetro reduzido TiZr com um ano de acompanhamento (Grupo Teste)

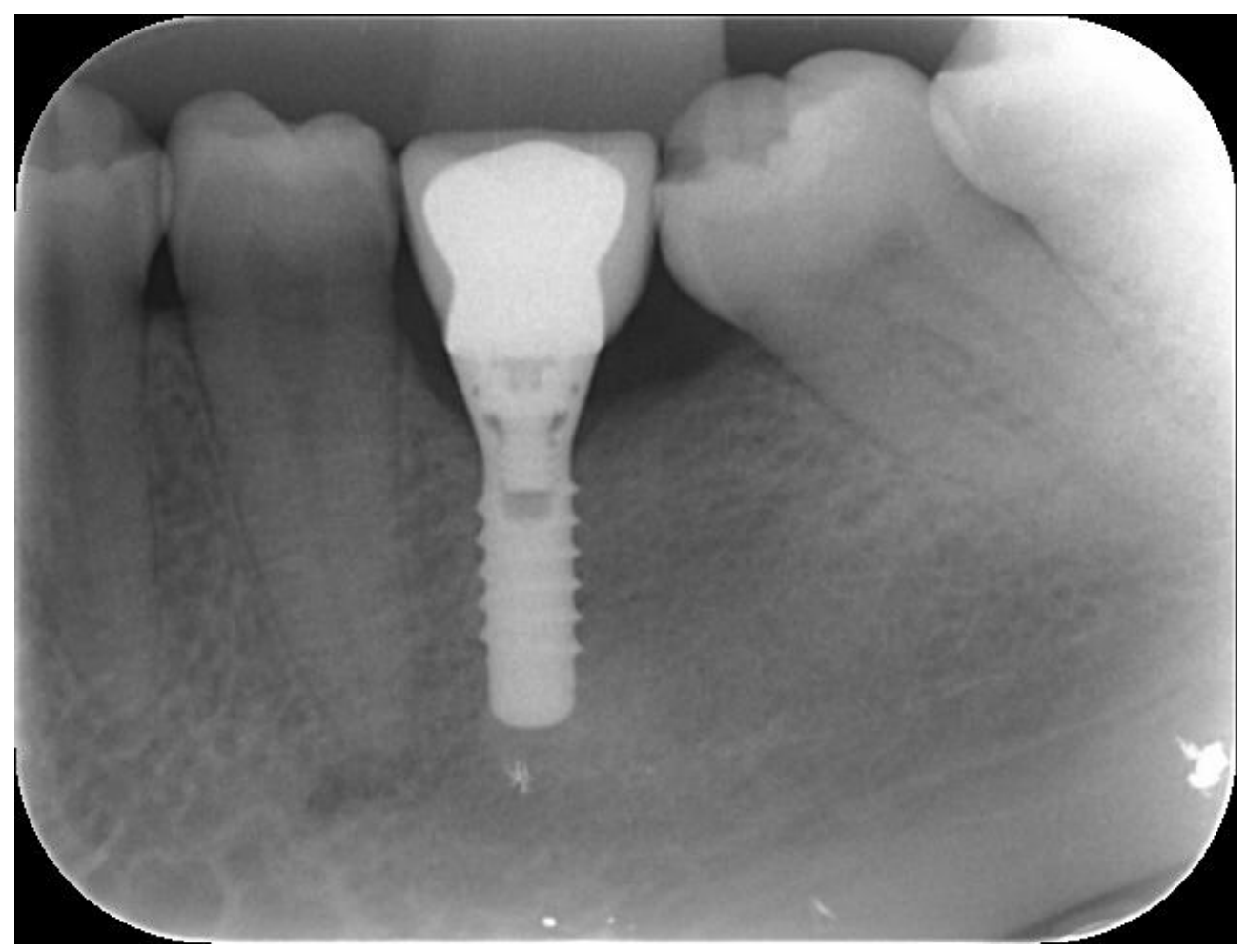

Figura 4.4- Imagem radiográfica mostrando uma coroa metalocerâmica unitária adaptada em um implante de diâmetro reduzido Ti com um ano de acompanhamento (Grupo Controle) 
A taxa de sobrevivência do implante foi definida pela permanência do implante em posição por pelo menos os 12 meses de acompanhamento. $O$ sucesso do implante foi definido de acordo com Karoussis et al. (2003) com base na ausência de (i) dor persistente, sensação de corpo estranho e/ou disestesia; (ii) infecção periimplantar com supuração; (iii) mobilidade (M); (iv) radiolucência contínua ao redor do implante; (v) profundidade clínica de sondagem (PCS) $\geq 5 \mathrm{~mm}$ associada com sangramento à sondagem (SS). A supuração periimplantar (S), o sangramento à sondagem (SS) e a profundidade clínica de sondagem (PCS) foram obtidas com o uso de sonda periodontal manual (William's probe, Hu-Friedy ${ }^{\circledR}$, Chicago, Estados Unidos). Mobilidade do implante (M), S e SS foram marcados como ausentes ou presentes. Além disso, a porcentagem da presença de placa bacteriana visível (PBV) nos diferentes sítios das próteses, e o índice de placa bacteriana (IPB) observada na boca toda foram determinados. Todas as variáveis descritas acima, com exceção da $\mathrm{M}$, foram medidas nos 4 aspectos dos implantes (mesial, distal, vestibular e lingual) aproximadamente duas semanas após a instalação das próteses (10 a semana), 3, 6, 9 e 12 meses após as próteses estarem em função. Todas as medidas clínicas e radiográficas foram realizadas por um examinador calibrado que não estava envolvido com os procedimentos cirúrgicos.

\section{Desfecho secundário}

O desfecho secundário foi representado pela taxa de sucesso das próteses sobre os implantes. O sucesso das próteses foi classificado de acordo com Pjetursson et. al em 2012, que foi definido como: (i) ausência de mobilidade na prótese (coroa ou intermediário); e (ii) falta de necessidade de reparo nas próteses no período 1 ano de acompanhamento.

\section{Calibração}

A calibração dos exames clínicos e radiográficos foi realizada para assegurar uma avaliação consistente dos implantes do estudo. Medidas clínicas dos tecidos moles (PCS e SS) e medidas radiográficas dos tecidos duros de 10 implantes, 5 de cada grupo, em pacientes escolhidos aleatoriamente, foram realizadas com 0 objetivo de calibrar o examinador. Cada medição foi realizada duas vezes em 2 dias 
diferentes, com um intervalo de, pelo menos, uma semana, em pacientes incluídos neste protocolo clínico. O coeficiente de correlação Kappa foi de 0,9 para as medidas clínicas e de 0,8 para o nível ósseo periimplantar marginal.

\section{Medida de erro radiográfico}

O erro radiográfico em relação a ausência do uso de posicionadores radiográficos padronizados também foi calculado. Em 4 pacientes foram realizadas 2 radiografias periapicais em cada um deles em um intervalo de uma semana. A medida do erro radiográfico foi de $0,02 \mathrm{~mm}$, o qual não foi significativo para o estudo (Al-Nawas et al., 2012).

\section{Análise estatística}

Valores médios e desvio padrão (DP) foram calculados para cada variável. Cada paciente foi considerado como unidade estatística. Comparações entre os grupos foram realizadas através da estatística descritiva. As diferenças nas alterações do nível ósseo marginal ao redor dos implantes entre os grupos foram analisadas pelo teste ANOVA para amostras pareadas e 0 valor de $p<0,05$ foi considerado como o nível de significância. Além disso, as taxas de sobrevivência e sucesso foram calculadas para cada grupo experimental e expressas em porcentagem. SS, M e S foram analisadas usando o teste Mann-Whitney's. PCS foi analisada usando o teste ANOVA. A curva de normalidade foi avaliada utilizando um teste de normalidade (Shapiro-Wilk test). 


\section{RESULTADOS}

Todos os implantes cicatrizaram sem intercorrências. No grupo Teste, 2 implantes eram de $10 \mathrm{~mm}$, e 8 de $8 \mathrm{~mm}$ de comprimento. Os valores correspondentes no grupo Controle eram 6 implantes de $10 \mathrm{~mm}$, e 4 de $8 \mathrm{~mm}$ de comprimento.

Após 1 ano de acompanhamento, todos os implantes sobreviveram, com uma taxa de sobrevivência de $100 \%$ para ambos os grupos. A taxa de sucesso dos implantes e das próteses para os grupos Teste e Controle também foi de $100 \%$. Os valores de M, SS, S, PBV e IPB avaliado na décima semana e um ano após as

próteses estarem em função são apresentados na Tabela 5.1. Supuração e mobilidade não foram constatadas em nenhum dos grupos. Não foi observada diferença estatisticamente significativa entre os grupos para as variáveis $M, S S$, S e $\operatorname{PBV}(p>0,05)$.

A média de PCS no GT no T1 e T2 foram, respectivamente, 2,47 $\pm 0,67 \mathrm{~mm}$ e $3,12 \pm 0,57$. Os valores correspondentes no GC foram de $2,12 \pm 0,62 \mathrm{~mm}$ e $3,05 \pm 0,78$ $\mathrm{mm}$ (Tabela 5.2). Não foi observada nenhuma diferença estatisticamente significativa entre os grupos em ambos os intervalos de tempo (Tabela 5.3).

A Tabela 5.4 mostra o nível ósseo marginal em T1 e T2 e a consequente média da perda óssea no T2. Os valores correspondentes da perda óssea marginal após 1 ano de acompanhamento foram $0,32 \pm 0,27 \mathrm{~mm}$ no GT e 0,35 $\pm 0,24 \mathrm{~mm}$ no GC. Não houve diferença estatisticamente significativa entre GT e CG $(p>0,05)$. 
Tabela 5.1- Porcentagem (\%) de M, SS, S, PBV, IPB avaliada na décima semana e um ano de função das próteses

\begin{tabular}{|c|c|c|c|c|}
\hline \multirow[b]{2}{*}{ Variáveis } & \multicolumn{2}{|c|}{ Décima Semana } & \multicolumn{2}{|c|}{ Um ano de função das próteses } \\
\hline & $\begin{array}{c}\text { Grupo Teste } \\
\text { (GT) }\end{array}$ & $\begin{array}{c}\text { Grupo Controle } \\
\text { (GC) }\end{array}$ & $\begin{array}{c}\text { Grupo Teste } \\
\text { (GT) }\end{array}$ & $\begin{array}{c}\text { Grupo Controle } \\
\text { (GC) }\end{array}$ \\
\hline M & 0 & 0 & 0 & 0 \\
\hline SS & 7 & 11 & 10 & 10 \\
\hline S & 0 & 0 & 0 & 0 \\
\hline PBV & 8 & 17 & 10 & 10 \\
\hline IPB & 28 & 28 & 24 & 24 \\
\hline
\end{tabular}

M, mobilidade; SS, sangramento a sondagem; S, supuração; PBV, placa bacteriana visível; IPB, índice de placa bacteriana. 
Tabela 5.2 - Profundidade clínica de sondagem (PCS) avaliada na décima semana de acompanhamento

\begin{tabular}{|c|c|c|c|c|c|c|c|c|c|c|c|c|c|c|}
\hline \multirow{3}{*}{ Sujeito } & \multicolumn{6}{|c|}{ Grupo Teste (GT) } & \multirow{3}{*}{$\begin{array}{l}\text { Média do } \\
\text { Implante }\end{array}$} & \multicolumn{7}{|c|}{ Grupo Controle (CG) } \\
\hline & \multicolumn{3}{|c|}{ Sítios vestibulares } & \multicolumn{3}{|c|}{ Sítios Linguais } & & \multicolumn{3}{|c|}{ Sítios Vestibulares } & \multicolumn{3}{|c|}{ Sítios Linguais } & \multirow{2}{*}{$\begin{array}{l}\text { Média do } \\
\text { Implante }\end{array}$} \\
\hline & $\mathrm{M}$ & $\mathrm{V}$ & $\mathrm{D}$ & $M$ & L & $\mathrm{D}$ & & $M$ & $\mathrm{~V}$ & $\mathrm{D}$ & $\mathrm{M}$ & $\mathrm{L}$ & $\mathrm{D}$ & \\
\hline 1 & 1 & 3 & 2 & 3 & 2 & 3 & 2,67 & 1 & 2 & 1 & 3 & 3 & 3 & 2,17 \\
\hline 2 & 1 & 1 & 1 & 2 & 2 & 2 & 1,67 & 2 & 3 & 3 & 3 & 2 & 2 & 2,50 \\
\hline 3 & 2 & 3 & 3 & 2 & 1 & 1 & 2,50 & 1 & 2 & 1 & 2 & 1 & 1 & 1,33 \\
\hline 4 & 2 & 1 & 1 & 1 & 2 & 3 & 2,00 & 4 & 4 & 4 & 2 & 2 & 4 & 3,33 \\
\hline 5 & 3 & 2 & 1 & 2 & 1 & 1 & 1,83 & 1 & 1 & 2 & 3 & 3 & 3 & 2,17 \\
\hline 6 & 1 & 2 & 1 & 2 & 1 & 1 & 1,50 & 1 & 2 & 3 & 1 & 1 & 2 & 1,67 \\
\hline 7 & 3 & 2 & 1 & 2 & 1 & 1 & 1,83 & 1 & 1 & 2 & 3 & 3 & 3 & 2,17 \\
\hline 8 & 3 & 2 & 3 & 1 & 2 & 2 & 2,67 & 2 & 1 & 3 & 1 & 3 & 3 & 2,17 \\
\hline 9 & 2 & 1 & 1 & 1 & 1 & 1 & 1,33 & 2 & 2 & 1 & 2 & 1 & 1 & 1,50 \\
\hline 10 & 3 & 3 & 3 & 3 & 2 & 3 & 3,33 & 2 & 3 & 3 & 1 & 2 & 2 & 2,17 \\
\hline Média (DP) & $\begin{array}{c}2,1 \\
(0,90)\end{array}$ & $\begin{array}{l}2,25 \\
(0,75)\end{array}$ & $2,0(1,00)$ & $1,9(0,79)$ & $1,5(0,52)$ & $1,8(0,94)$ & $2,47(0,67)$ & $1,7(0,97)$ & $2,1(1,00)$ & $2.3(1,06)$ & $2,1(0,90)$ & $2,1(0,90)$ & $2,4(0,97)$ & $2,12(0,62)$ \\
\hline Mediana & 2,1 & 2,25 & 2,0 & 1,9 & 1,50 & 1,8 & 2,47 & 1,7 & 2,1 & 2,3 & 2,1 & 2,1 & 2,4 & 2,12 \\
\hline
\end{tabular}


Tabela 5.3 - Profundidade clínica de sondagem (PCS) avaliada com 1 ano de acompanhamento

\begin{tabular}{|c|c|c|c|c|c|c|c|c|c|c|c|c|c|c|}
\hline \multirow{3}{*}{ Sujeito } & \multicolumn{6}{|c|}{ Grupo Teste (GT) } & \multirow{3}{*}{$\begin{array}{l}\text { Média do } \\
\text { Implante }\end{array}$} & \multicolumn{7}{|c|}{ Grupo Controle (GC) } \\
\hline & \multicolumn{3}{|c|}{ Sítios Vestibulares } & \multicolumn{3}{|c|}{ Sítios linguais } & & \multicolumn{2}{|c|}{$\begin{array}{c}\text { Sítios } \\
\text { Vestibulares }\end{array}$} & \multicolumn{4}{|c|}{ Sítios Linguais } & \multirow[t]{2}{*}{$\begin{array}{l}\text { Média } \\
\text { do } \\
\text { Implante }\end{array}$} \\
\hline & $M$ & V & D & $M$ & L & D & & $M$ & V & D & $\mathrm{M}$ & L & D & \\
\hline 1 & 3 & 2 & 3 & 3 & 2 & 3 & 3,17 & 2 & 2 & 3 & 3 & 2 & 3 & 3,00 \\
\hline 2 & 3 & 3 & 3 & 4 & 1 & 2 & 3,17 & 3 & 3 & 3 & 4 & 2 & 3 & 3,50 \\
\hline 3 & 2 & 3 & 3 & 4 & 4 & 3 & 3,67 & 2 & 3 & 3 & 3 & 3 & 4 & 3,50 \\
\hline 4 & 3 & 4 & 4 & 3 & 2 & 5 & 4,17 & 5 & 4 & 4 & 3 & 4 & 4 & 4,67 \\
\hline 5 & 3 & 3 & 4 & 2 & 2 & 2 & 3,33 & 3 & 2 & 2 & 3 & 4 & 3 & 3,17 \\
\hline 6 & 1 & 3 & 3 & 3 & 2 & 2 & 2,83 & 3 & 2 & 3 & 1 & 2 & 1 & 2,50 \\
\hline 7 & 3 & 2 & 3 & 2 & 1 & 2 & 2,67 & 2 & 2 & 3 & 3 & 1 & 2 & 2,67 \\
\hline 8 & 2 & 2 & 3 & 3 & 1 & 2 & 2,67 & 3 & 3 & 2 & 3 & 1 & 4 & 3,00 \\
\hline 9 & 1 & 3 & 2 & 3 & 1 & 1 & 2,17 & 3 & 1 & 1 & 1 & 1 & 2 & 1,67 \\
\hline 10 & 3 & 3 & 3 & 3 & 2 & 3 & 3,33 & 3 & 3 & 3 & 1 & 2 & 2 & 2,83 \\
\hline Média(DP) & $2,4(0,84)$ & $\begin{array}{l}2,80 \\
(0,63)\end{array}$ & $3,1(0,57)$ & $3,0(0,67)$ & $1,8(0,92)$ & $2,5(1,08)$ & $3,12(0,57)$ & $2,9(0,88)$ & $2,0(0,85)$ & $2,0(0,82)$ & $\begin{array}{c}2,50 \\
(1,08)\end{array}$ & $2,2(1,14)$ & $\begin{array}{c}2,80 \\
(1,03)\end{array}$ & $3,05(0,28)$ \\
\hline Mediana & 2,4 & 2,8 & 3,1 & 3,0 & 1,8 & 2,5 & 3,12 & 2,9 & 2,5 & 2,7 & 2,5 & 2,0 & 2,80 & 3,05 \\
\hline
\end{tabular}


Tabela 5.4 - (a) Resultados do nível ósseo periimplantar marginal observados na radiografia imediatamente após a colacação das proteses (T1), e após 1 ano das próteses em função (T2). (b) Resultados da perda do nível ósseo periimplantar marginal entre T1 e T2

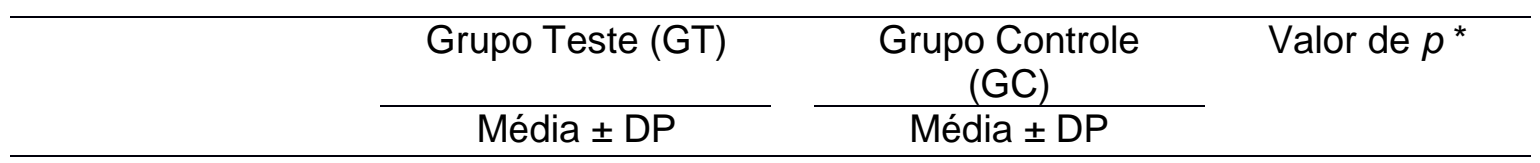

(a) Nível ósseo periimplantar marginal (mm)

$\mathrm{T} 1$

$\begin{array}{llll}\text { Mesial (DP) } & 0,10(0,18) & 0,08(0,22) & 0,99 \\ \text { Distal (DP) } & 0,20(0,36) & 0,04(0,13) & 0,29 \\ \text { Média (DP) } & 0,16(0,26) & 0,06(0,17) & 0,54\end{array}$

T2

$\begin{array}{llll}\text { Mesial (DP) } & 0,32(0,29) & 0,43(0,31) & 0,73 \\ \text { Distal (DP) } & 0,64(0,62) & 0,38(0,24) & 0,18 \\ \text { Média (DP) } & 0,48(0,33) & 0,41(0,27) & 0,90\end{array}$

(b) Perda do nível ósseo periimplantar marginal

T2

$\begin{array}{llll}\text { Mesial (DP) } & 0,22(0,18) & 0,35(0,22) & 0,46 \\ \text { Distal (DP) } & 0,44(0,36) & 0,34(0,25) & 0,15 \\ \text { Média (DP) } & 0,32(0,27) & 0,35(0,24) & 0,60\end{array}$

${ }^{*}$ Resultados do teste ANOVA; (não há diferença estatisticamente significante $p>0,05$ ). 


\section{DISCUSSÃO}

O presente estudo clínico randomizado e controlado avaliou implantes de diâmetro reduzido confeccionados em uma liga de titânio/zircônio ou titânio puro instalados em regiões posteriores da mandíbula. Foi demonstrado que os IDRs em ambos os grupos exibiram resultados semelhantes em relação a perda óssea marginal ao redor dos implantes após um ano de acompanhamento. Além disso, não houve falhas nos implantes durante este curto período de acompanhamento e a média de valores de PCS, SS, S, PV e M também foram similares entre os grupos.

A força do presente estudo reside no rígido desenho metodológico utilizado. Várias precauções foram tomadas de modo a eliminar possíveis fatores confundidores na avaliação da perda óssea marginal. Os IDRs experimentais utilizados neste estudo são idênticos (forma, tratamento da superfície, etc), com excessão do material usado em sua fabricação. $O$ desenho de boca dividida assegurou que os resultados de ambos IDRs pudessem ser avaliados de forma pareada no mesmo paciente. Os IDRs foram instalados em sítios de reabilitação unitários com dentes vizinhos saudáveis, localizados em regiões contralaterais de molares mandibulares ocluindo em dentes antagonistas saudáveis (Figuras $4.3 \mathrm{e}$ 4.4). Assim, possíveis variáveis relacionadas ao sítio do implante, que poderiam influenciar o cálculo da perda óssea marginal foram minimizadas, e os pontos de referência nas radiografias puderam ser mais facilmente identificados durante a mensuração. Além disso, o programa de controle de placa bacteriana, que demandou que os pacientes retornassem á clínica a cada três meses para receberem profilaxia, associcado às instruções de higiene oral detalhadas fornecidas, assegurou que a perda óssea marginal encontrada não era induzida por doença. Os níveis de placa bacteriana foram mantidos baixos durante todo o período do experimento (Tabela 5.1).

Tal regime de investigação rigorosa difere dos estudos clínicos anteriores que avaliaram os implantes da liga de titânio/zircônio nas regiões posteriores dos maxilares. Nestes experimentos, os IDRs estavam esplintados a implantes de diâmetro regular (Barter et al., 2012) ou instalados em região anterior e posterior dos maxilares, suportando diferentes tipos de próteses (Chiapasco et al., 2012; Akça et al., 2013; Benic et al., 2013). 
A perda óssea marginal nas faces interproximais dos implantes foi de aproximadamente $0,3 \mathrm{~mm}$ em ambos os grupos Teste e Controle. Este achado está de acordo com os resultados reportados em estudos clínicos realizados anteriormente no qual implantes de diâmetro reduzido de titânio/zircônio foram avaliados em diferentes sítios (Al-Nawas et al., 2012; Barter et al., 2012; Chiapasco et al., 2012; Benic et al., 2013). Em um recente estudo controlado e randomizado em que IDRs Ti e TiZr foram comparados (Al-Nawas et al., 2012), um total de 182 implantes foram instalados em regiões interforaminais em 91 pacientes para suportar sobredentaduras. Após 1 ano de acompanhamento, não foi observado diferenças entre os IDRs TiZr e Ti em relação a mudança no NOM avaliados nas radiografias $(0,3 \mathrm{~mm})$ e na taxa de sobrevivência destes implantes. Em um outro estudo, foram instalados 51 IDRs em 18 pacientes (Chiapasco et al., 2012). Os resultados demonstraram no final do período de observação que falhas nos implantes não foram observadas. Os valores da perda óssea marginal ao redor dos implantes observada nas radiografias variou de 0 a $1 \mathrm{~mm}$. Deste modo, o nível ósseo marginal nos IDRs feitos da liga de TiZr e Ti foram similares.

O presente estudo demonstrou uma alta taxa de sucesso e sobrevivência dos IDRs instalados na região de molares da mandíbula. Este achado corroborou com diversos estudos clínicos similares (Vigolo; Givani 2000; Vigolo et al., 2004; Zinsli et al., 2004; Comfort et al., 2005; Romeo et al., 2006). Zinsli et al. (2004) em um estudo clínico prospectivo, avaliaram 298 implantes Ti de diâmetro reduzido. Os autores reportaram que 2 implantes fraturaram após 2 e 6 anos, respectivamente, e que a taxa de sobrevivência cumulativa em 5 anos de acompanhamento foi de 98,7\%. Em um outro estudo longitudinal em que 122 IDRs foram avaliados e acompanhados por um período de 7 anos, Romeo et al. (2006) observaram que as taxas cumulativas de sobrevivência foram de $98,1 \%$ na maxila e $96,9 \%$ na mandíbula. Os autores também demonstraram uma alta taxa de sucesso, de $96,1 \%$ na maxila e $92 \%$ na mandíbula. Tolentino et al. (2013), avaliaram e compararam clinicamente coroas unitárias em IDRs TiZr e $\mathrm{Ti}$ instalados em regiões de pré-molares e molares na maxila e mandíbula. Após 1 ano de acompanhamento, as taxas de sucesso e sobrevivência foram similares entre os diferentes tipos de implantes. Desta forma, a evidência que emerge da literatura parece sugerir que o uso de IDRs para suportar coroas unitárias em regiões posteriores dos maxilares promove altas taxas de sucesso e sobrevivência. 
A taxa de sucesso das próteses unitárias instaladas nos IDRs de liga de titânio/zircônio ou titânio puro foi de $100 \%$ no presente estudo. Embora este achado esteja de acordo com estudos prévios (Vigolo et al., 2004; Barter et al., 2012; Akça et al., 2013; Tolentino et al., 2013), é importante salientar que os resultados deste estudo estão limitados a um curto período de acompanhamento de um ano. Uma recente revisão sistemática reportou que falhas nas reconstruções protéticas começam a se tornar mais prevalentes após 5 anos de acompanhamento (Jung et al., 2012). Afrouxamento do parafuso e intermediário, perda de retenção (fratura do cemento resinoso) e fratura do material de revestimento são as complicações técnicas mais comuns. Assim, pode-se sugerir que IDRs com 1 ano de acompanhamento após as próteses estarem instaladas não estão propensos a complicações protéticas.

$O$ presente estudo falhou em demonstrar que IDRs feitos de TiZr são superiores aos IDRs feitos de Ti. A avaliação das diversas variáveis clínicas demonstrou que não houve diferenças significativas entre os dois implantes experimentais. Esses achados não estão de acordo com modelos de estudos laboratoriais e em animais que compararam esses dois implantes. Estudos in vitro demonstraram que implantes fabricados com a liga titânio/zircônio são capazes de suportar tensões mecânicas maiores do que aqueles fabricados com titânio puro (Gahlert et al., 2009; Thoma et al., 2011; Barter et al., 2012; Chiapasco et al., 2012; Kammerer et al., 2013). Além disso, estudos pré-clínicos demonstraram que implantes da liga TiZr exibiram maior contato osso/implante em ratos ovariectomizados (Wen et al., 2013), e maior torque para remoção do implante em pequenos porcos (Gottlow et al., 2012) do que implantes de titânio puro. Embora o sucesso do uso de IDRs feitos de titânio puro instalados em regiões posteriores dos maxilares tenha sido reportado após 10 anos de acompanhamento (Garcez et al., 2014), os estudos mencionados acima sugerem que diferenças entre os dois implantes em termos de resistência podem surgir em condições extremas. 


\section{CONCLUSÕES}

Os resultados do presente estudo clínico e radiográfico demonstraram que os IDRs TiZr obtiveram um desempenho semelhante aos IDRs $\mathrm{Ti}$ em relação a mudança no nível ósseo periimplantar marginal após 1 ano de acompanhamento. Além disso, não foram identificadas diferenças quanto aos parâmetros clínicos entre os dois grupos. Desta forma, este trabalho sugere que IDRs feitos da liga titânio/zircônio ou de titânio puro, podem ser igualmente usados para suportar coroas unitárias em regiões posteriores da mandíbula. No entanto, é necessário que estudos com maior tempo de acompanhamento sejam realizados para confirmar estes achados. 


\section{REFERÊNCIAS ${ }^{1}$}

Adell R, Eriksson B, Lekholm U, Branemark PI, Jemt T. A long-term follow-up study of osseointegrated implants in the treatment of the totally edentulous jaw. Int $\mathrm{J}$ Oral Maxillofac Implants. 1990;5:347-59.

Akça K, Yeliz Ç, Serdar U, Murat CÇ. A Prospective, Open-Ended, Single-Cohort Clinical Trial on Early Loaded Titanium-Zirconia Alloy Implants in Partially Edentulous Patients: Up-to-24-Month Results. Int J Oral Maxillofac Implants. 2013;28:573-78.

Albrektsson T. A multicenter report on osseointegrated oral implants. J Prosthet Dent. 1988;60: 75-84.

Allum SR, Tomlinson RA, Joshi R. The impact of loads on standard diameter, small diameter and mini implants: a comparative laboratory study. Clin Oral Implants Res. 2008;19: 553-9.

Al-Nawas B, Bragger U, Meijer HJ, Naert I, Persson R, Perucchi A, Quirynen M, Raghoebar, GM, Reichert TE, Romeo E, Santing HJ, Schimmel M, Storelli S, Bruggenkate CT, Vandekerckhove B, Wagner W, Wismeijer D, Muller F. A doubleblind randomized controlled trial (rct) of titanium-13zirconium versus titanium grade iv small-diameter bone level implants in edentulous mandibles - results from a 1-year observation period. Clin Implant Dent Relat Res. 2012;14: 896-904.

Andersen E, Saxegaard E, Knutsen MB, Haanaes HR. A prospective clinical study evaluating the safety and effectiveness of narrow-diameter threaded implants in the anterior region of the maxilla. Int J Oral Maxillofac Implants. 2001;2: 217-24.

Barter S, Stone P, Bragger U. A pilot study to evaluate the success and survival rate of titanium-zirconium implants in partially edentulous patients: results after 24 months of follow-up. Clin Oral Implants Res. 2012;23: 873-81.

Benic GI, Gallucci GO, Mokti M, Hamerle CHF, Weber HP, Jung RE. Titaniumzirconium narrow-diameter versus titanium regular-diameter implants for anterior and premolar single crowns: 1-year results of a randomized controlled clinical study. J Clin Periodontol. 2013;40: 1052-61.

\footnotetext{
${ }^{1}$ De acordo com Estilo Vancouver.
} 
Berglundh T, Persson L, Klinge B. A systematic review of the incidence of biological and technical complications in implant dentistry reported in prospective longitudinal studies of at least 5 years. J Clin Periodontol. 2002;3:197-212.

Branemark PI, Zarb GA, Albrektsson T. Tissue integration prostheses. Quintessence: Publishing Co; 1985.

Carlsson GE, Lindquist LW, Jemt T. Long-term marginal peri-implant bone loss in edentulous patients. Int J Prosthodont. 2000;13:295-302.

Chiapasco M, Romeo E, Vogel G. Vertical distraction osteogenesis of edentulous ridges for improvement of oral implant positioning: a clinical report of preliminary results. The Int J Oral Maxillofac Implants. 2001;16:43-51.

Chiapasco M, Casentini P, Zaniboni M, Corsi E, Anello T. Titanium-zirconium alloy narrow diameter implants (Straumann Roxolid( $\AA$ ) for the rehabilitation of horizontally deficient edentulous ridges: prospective study on 18 consecutive patients. Clin Oral Implants Res. 2012;23:1136-41.

Comfort MB, Chu FCS, Chai J, Wat PYP, Chow TW. A 5-year prospective study on small diameter screw-shaped oral implants. J Oral Rehabil. 2005;5: 341-5.

Davarpanah M, Martinez H, Tecucianu JF, Celletti R, Lazzara R. Small-diameter implants: indications and contraindications. Int J Esthet Dent. 2000;12: 186-94.

Esposito M, Hisrsch JM, Lekholm U, Thomsen P. Biological factors contributing to failures of osseointegrated oral implants. Etiopathogenesis. Eur J Oral Sci. 1998a;106: 527-51.

Esposito M, Hisrsch JM, Lekholm U, Thomsen P. Biological factors contributing to failures of osseointegrated oral implants. Etiopathogenesis. Eur J Oral Sci. 1998b;106: 721-64.

Flanagan D. Fixed partial dentures and crowns supported by very small diameter dental implants in compromised sites. Implant Dent. 2008; 17:182-91. 
Friberg B, Ekestubbe A, Sennercy L. Clinical outcome of Bränemark System implants of variuos diameters: a retrospective study. Int J Oral Maxillofac Surg. 2002; 17:6717.

Gahlert, M, Rohling S, Wieland M, Sprecher CM, Kniha H, Milz S. Clin Oral Implants Res. 2009; 20:1247-53.

Garcez JA, Mendonça CG, Sukekava F, Conceição A, Araujo MG. Uso de implantes dentários de diâmetro reduzido na região posterior dos maxilares. Estudo retrospectivo de até 8 anos. Rev Dent Press Period Implant. 2008; 2: 39-45.

Garcez JA, Tolentino LS, Sukekava F, Seabra M, Cesar-Neto JB, Araujo MG. Longterm outcomes from implants installed by using split-crest technique in posterior maxillae: 10 years of follow-up. Clin Oral Implants Res. 2014; Jan 0: 1-6 [Epub ahead of print]

Gottlow J, Dard M, Kjellson F, Obrecht M, Sennerby L. Evaluation of a New TitaniumZirconium Dental Implant: A Biomechanical and Histological Comparative Study in t he Mini Pigs. Clin Oral Implants Res. 2012;14: 538-45.

Hammerle C, Bragger U, Schmid B, Lang NP. Successful bone formation at immediate transmucosal implants. Int J Oral Maxillofac Implants. 1998;13: 522-30.

Ikarashi $\mathrm{Y}$, Toyoda K, Kobayashi E, et al.. Improved biocompatibility of TitaniumZirconium (Ti-Zr) Alloy: tissue reaction and sensitization to Ti-Zr Alloy compared with pure $\mathrm{Ti}$ and $\mathrm{Zr}$ in rat implantation study. Material Transactions. 2005; 46:2260-7.

Ivanoff C J, Sennrby L, Johansson C, Rangert B, Lekholm U. Influence of implant diameters on the integration of screw implants. An experimental study in rabbits. Int $\mathrm{J}$ Oral Maxillofac Implants. 1997; 26:141-8.

Jorneus $\mathrm{H}$. Developing the narrow platform. The nobel Biocare Global Forum. 1996;10:3.

Jung RE, Zembic A, Pjetursson BE, Zwahlen M, Thoma DS. Systematic review of the survival rate and the incidence of biological, technical, and aesthetic complica- tions of single crowns on implants reported in longitudinal studies with a mean follow-up of 5 years. Clin Oral Implants Res. 2012; 23 (Suppl. 6): 2-21. 
Kammerer PW, Palarie V, Schiegnitz E, Hagmann S, Alshihri A, Al-Nawas B. Vertical osteoconductivity and early bone formation of titanium-zirconium and titanium implants in a subperiosteal rabbit animal model. Clin Oral Implants Res. 2013;00: 17. [Epub ahead of print]

Lekholm, U, Steenberghe DV, Herrmann I, Bolender C, Folmer T, Gunne J, Henry P, Higuchi K, Laney WR, Linden U. Osseointegrated implants in the treatment of partially edentulous jaws: a prospective 5-year multicenter study. Int J Oral Maxillofac Implants. 1994;9: 627-35.

Nedir R, Nurdin N, Szmukler-Moncler S, Bischof M. Placement of tapered implants using an osteotome sinus floor elevation technique without bone grafiting: 1-year results. Int J Oral Maxillofac Implants. 2009;24: 727-33.

Polizzi G, Fabbro S, Furri M, Herrmann I, Squarzoni S. Clinical application of narrow Branemark System implants for single-tooth restorations. Int $\mathrm{J}$ Oral Maxillofac. 1999;14: 496-503.

Quek CE, Tan KB, Nicholls Jl. Load fatigue performance of a single-tooth implant abutment system: effect of diameter. Int J Oral Maxillofac Implants. 2006;21: 929-36.

Romeo E, Lops D, Amorfini L, Chiapasco M, Chiosolfi M, Vogle G. Clinical and radiographic evaluation of small-diameter $(3.3 \mathrm{~mm})$ implants followed for $1-7$ years: a longitudinal study. Clin Oral Implants Res. 2006;17: 139-48.

Saulacic N, Bosshardt DD, Bornstein MM, Berner S, Buser D. Bone apposition to a titanium-zirconium alloy implant, as compared to two other titanium-containing implants. Eur Cell Mater; 23:273-86.

Sista S, Wen C, Hodgson PD, Pandey G. The influence of surface energy of titanium-zirconium alloy on osteoblast cell functions in vitro. J Biomed Mater Res A. 2011 [Epub ahead of print]

Steinemann SG. Titanium - the material of choice? Periodontol 2000. 1998;17: 7-21.

Stone P. Experience new confidence and freedom with small diameter implants. Europerio 6. Stockholm, Sweden, 2009;June 4-6. 
Thoma DS, Jones AA, Dard M, Grize L, Obrecht M, Cochran DL. Tissue integration of a new titanium-zirconium dental implant: A comparative histologic and radiographic study in the canine. J Clin Periodontol. 2011;82:1453-61.

Tolentino LS, Sukekava F, Seabra M, Lima LA, Garcez-Filho J, Araújo MG. Success and survival rates of narrow diameter implants made of titanium-zirconium alloy in the posterior region of the jaws - results from a 1-year follow-up. Clin Oral Implants Res. 2013 25: 137-41.

Vigolo P, Givani A. Clinical evaluation of single-tooth mini-implant restorations: a fiveyear retrospective study. J Prosthet Dent. 2000;84: 50-4.

Vigolo P, Givani A, Majzoub Z, Cordioli G. Clinical evaluation of small-diameter implants in single-tooth and multiple-implant restorations: a 7-year retrospective study. Int J Oral Maxillofac Implants. 2004;19: 703-9.

Wen B, Feng Z, Zhen L, Peng Z, Xingnan L, Michel D. The osseointegration behavior of titanium-zirconium implants in ovariectomized rabbits. Clin Oral Implants Res. 2013;00: 1-7 [Epub ahead of print]

Zinsli B, Sagesser T, Mericske E, Mericske-Stern R. Clinical evaluation of smalldiameter ITI implants: a prospective study. Int J Oral Maxillofac Implants. 2004;19: 92-9. 
ANEXO A - Parecer Emitido Comitê de Ética em Pesquisa em Humanos da Universidade Federal de Sergipe

\section{UNIVERSIDADE FEDERAL DE SERGIPE}

COMITÊ DE ÉTICA EM PESQUISA ENVOLVENDO SERES HUMANOS

CAMPUS DA SAÚDE PROF. JOÃO CARDOSO NASCIMENTO JR

Rua Cláudio Batista S/N- Centro de Pesquisas Biomédicas - Bairro Sanatório

CEP: 49060-100 Aracaju -SE / Fone:(79) 2105-1805

E-mail: cephu@ufs.br

\section{$D E C L A R A C \tilde{A} O$}

Declaro, para os devidos fins, que o Protocolo de Pesquisa intitulado:“ESTUDO COMPARATIVO DA VARIAÇÃo DO NÍVEL ÓSSEO MARGINAL AO REDOR DE IMPLANTES CONFECCIONADOS EM TITANIO PURO E UMA LIGA DE TITANIO E ZIRCONIA" - N CAAE - 0025.0.107.000-11, sob orientz̧̄o da pesquisador João de Andrade Garcez Filho, foi aprovado pelo Comi€ de Ética em Pesquisa da Universidade Federal de Sergipe- CEP/UFS em reunão realizada dia 06/05/2011.

Cabe ao pesquisador apresentar ao CEP/UFS os relabrios parciais e final sobre a pesquisa (Res. CNS 196/96).

Aracaju, 17 de maio de 2011.

Prof. Dr. Manuel Herninio de Aguiar Oliveira

Coordenador do CEP/UFS 


\title{
ANEXO B - Parecer Emitido pelo Comitê de Ética em Pesquisa em Humanos da Universidade de São Paulo
}

\author{
UNIVERSIDADE DE SĀO PAULO \\ FACULDADE DE ODONTOLOGIA \\ Comitê de Ética em Pesquisa
}

153-MTW

Sâo Paulo, 25 de maio de 2012

DECLARAÇÃO

Em atendimento à solicitaçâo dos pesquisadores Luiz Antônio Alves de Lima (orientador) e Livia de Souza Tolentino (pós-graduanda), responsáveis pelo projeto de pesquisa intitulado "Estudo comparativo da variaçăo do nivel ósseo marginal ao redor de implantes confeccionados em titânio puro e uma liga de titânio e zircônio", o Comitê de Ética em Pesquisa da Faculdade de Odontologia da Universidade de Săo Paulo analisou a documentaçáo enviada, verificando que o referido projeto teve seus aspectos éticos avaliados pelo Comitê de Etica em Pesquisa da Universidade Federal de Sergipe (CEPUFS), tendo seu protocolo sido aprovado em 6 de maio de 2011 sob registro CAAE 2011 0025.0.107.000-11. Como foi do entendimento deste CEP, durante sua reunião realizada em 25 de maio de 2012, decidiu-se dar ciência da aprovaçăo anterior, nâo havendo nenhuma oposiçâo por parte deste CEP com relaçâo a sua realizaçâo.

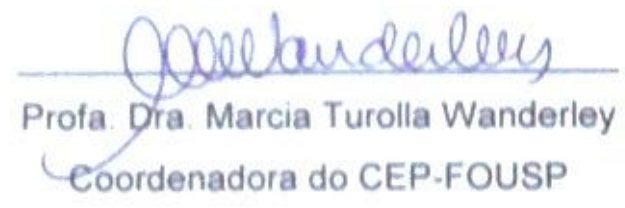

